\title{
UNRAVELING ATTITUDES ON ENTREPRENEURIAL UNIVERSITIES: THE CASE OF CROATIAN AND SPANISH UNIVERSITIES
}

\author{
'Given that they are situated at the cross roads of research, education and innovation, \\ universities in many respects hold the key to the Knowledge Economy and Society' \\ EC, 'The Role of Universities in the Europe of Knowledge'
}

\section{ABSTRACT}

The objective of this paper is to present evidence that there are different types of supportive faculty members. We conducted a case study on a sample of Croatian and Spanish universities by using an already tested ENTRE-U scale for measuring the faculty members' attitudes. These two scenarios are quite different in terms of their innovation systems, economic context and university system. We tested and found no evidence of any statistically significant difference due to the country. These two facts suggest the possible existence of an isomorphic trajectory when implementing entrepreneurial universities regardless the context. University managers should be aware of the existence of three different types of supportive individuals. Each of these groups requires a certain program of human resource development. This shifts the debate to how entrepreneurial universities should manage the tensions arising from the need of some degree of specialization in any of the three roles of the faculty members, namely teaching, researching and transfer of the knowledge stemming from research results.

KEYWORDS: entrepreneurial university; entrepreneurial orientation; attitude; university government 


\section{Introduction}

The world today is more closely knit, using different means of education, organisation, communication and production, and is more exposed to rapid change than ever before. Universities play a vital role for the development of European regions (Guerrero et al. 2014). They are instrumental to increasing the global competitiveness of the European Union (Guerrero, Cunnigham and Urbano 2015). Higher education institutes and universities create jobs, firms and social cohesion (Van Doorn, 2013). Moreover, they are the focal point of knowledge creation, innovation and entrepreneurship, all of which are the areas in which the EU has set ambitious objectives (Wissema, 2009). All over the world and throughout Europe, higher education institutions represent a nexus between needs and opportunities.

Entrepreneurialism in higher education has a history: itself the subject of prolific research going back beyond Burton Clark's 1998 classic. However, it has gained increasing impetus recently because of: the growing importance of the 'knowledge economy' sectors; promotion by national governments and the EC in Europe (Gibb 2012). This transformation has given significant pressure on interaction between government, university, society and private sector (Heng et al., 2012, Altmann and Ebersberger, 2013). With traditional role of education: research and transfer of knowledge become more essential (Wright, Clarysse, Lockett \& Knockaert M. 2008). As universities become more entrepreneurial (Etzkowitz and Leydesdorff, 1996, 2000; Gibbons et al., 1994), several challenges have been identified. Not only do we still lack a clear definition of what an entrepreneurial university is, but also there is no shared culture among the key actors who must face the challenge of the required shift: the faculty members. Perhaps we do not need a robust theoretical definition; instead, what might serve best is a deeper understanding of what this really entails, according to the key role that universities have come to (must, we should say) play in the current economy (Etzkowitz, 1998). The lack of entrepreneurial role models, the absence of an entrepreneurial culture across the institution, and the reward system are some of the main barriers, as described by Philpott et al. (2011). They seem to lead universities to hybrid practices, as Etzkowitz and Leydesdorff (2000) and Tuunainen (2005) labeled them. The entrepreneurial activities at universities are affected by changes in two important factors: the funding structure and expectations, which affect the interest of 
starting new firms and the understanding of new commercialization techniques (Rasmussen et al., 2006). However; acquiring an entrepreneurial character in academic institutions faces challenges associated with the "entrepreneurial culture.". These situations make academic activities negatively influence the entrepreneurial activity (Philpott et al., 2011).

Entrepreneurial orientation has been usually measured by some kind of "entre-scales" throughout the literature on entrepreneurship applied to the private sector. Khandwalla (1977) and the subsequent work of Miller and Friesen (1978), as well as that of Miller (1983), are reputed to be the origins of one of the most used scales: the entre-scale. Other similar scales have been used in several studies (Covin and Slevin, 1986, 1989; Covin and Covin, 1990) for measuring the entrepreneurial orientation in the context of business organizations.

However, we lacked a useful scale for measuring entrepreneurial orientation in universities until Todorovic et al. $(2005,2011)$ developed and tested the existence of some dimensions in the entrepreneurial orientation latent construct. The building process of their scale (Entre-U) is fully explained in Todorovic et al. $(2005,2011)$. Those authors concluded that four main constructs explain the latent construct of the entrepreneurial orientation of a university department and predicted the results on spinouts and patents. Accordingly, the four key dimensions are as follows:

- Unconventionality, a similar although different idea to "risk-taking," deals with how researchers or department or university staff try to explore new (sometimes unconventional) ways to get their objectives.

- Industry collaboration refers to how the department, faculty, and university engage with the business system.

- University policies deal with the culture of the university as well as organizational and strategic issues.

- Research mobilization deals with how the university, as a whole, shares its research with external agents. It implies a shift in knowledge management from researchers towards communities, thus a diffusion of knowledge from the group. 
Such dimensions are different but related. Todorovic et al. (2011) suggested that facilitating one dimension while discouraging others would lead to an unsuccessful implementation of the entrepreneurial university philosophy. Moreover, they considered the "entrepreneurial orientation of the department" as a second-level construct and hence they needed proxy variables for measuring it, in order to predict spinout and patent results.

Nevertheless, we argue that the entrepreneurial orientation of the department can be measured directly when trying to measure the individual's attitudes (i.e., his or her entrepreneurial orientation) from the 47 variables the authors initially developed, instead of measuring indirectly the orientation of the department.

In fact, Martinelli et al. (2008) had put the focus on the faculty side. They analyzed attitudes towards the engagement of university with industry by mapping the network of linkages from the faculty perspective. They found a considerable number of researchers engaged in knowledge exchange processes with industry and other non-academic partners. They also found relevant differences regarding the faculty attitudes towards technology transfer and awareness of the university's policies. We may infer from their work that several attitudinal groups exist within the same faculty and even within the same department.

In order to provide some responses to these issues, our study aims at presenting evidence of whether there are different types of supportive faculty members and, in the event of a positive response, what their characteristics are. For this aim we surveyed a sample of Croatian and Spanish universities by using the ENTRE-U scale for measuring the faculty members' attitudes, which has been developed by Todorovic et al. (2005, 2014). These two scenarios are quite different in terms of their innovation systems, economic context and university system. Therefore, we are seeking for obtaining the shared characteristics between these two scenarios so we can reach a conclusion regarding the existence of a certain type of faculty members supporting the entrepreneurial university. This will enable conducting future research on whether there 
is an isomorphic trajectory for universities to become more entrepreneurial based on the existence of these groups in other contexts. Since we use an already tested scale, this study can be reproduced in other countries to obtain a comparison of results.

Our findings will also be beneficial for university managers. Knowing what type of groups there are and their characteristics will ease the implementation of more adequate programmes in the quest for regional growth based on the triple-helix paradigm. This may imply decisions relative to the university portfolio in terms of teaching, researching and transfer or contracts with external agents. It also suggests the need for shifting the debate towards the extent to what a faculty member should specialize in any of the three core duties or even whether he/she should undertake a certain combination of those duties in order to obtain a superior performance. This is an issue that can be better addressed in combination with scholars in the field of high performance teams.

\section{LITERATURE REVIEW}

Intellectual property disclosed to and registered by transfer technology office from that time became principal way to systematic exaggeration of commercialization and innovation inventing from university research (Thursby\& Thursby, 2005). Hence, universities around world try to increase they impact in society and number of patents disclosures in behalf of their university. Aldridge \& Audretsch (2011) pointed out that entrepreneurial society exists where entrepreneurship is a key to economic growth \& development and is promoted by institutions conducive to entrepreneurial activity. Kerr and Nanda (2009) associate admission to financial resources with positively influence on entrepreneurship for high-tech \& knowledge industries.

An entrepreneurial university means that research groups act as quasi-firms when undertaking and managing their activities. Bok (2003, p. 3), when writing about the commercialization of higher education, talks about the efforts within a university of making a profit from teaching, research and other university activities. In debate of 
academic entrepreneurship, studies have traditionally classified the faculty members depending on their attitudes relative to the idea of developing a more entrepreneurial university. This has led to two opposed groups, namely supportive entrepreneurial role of university (Harris and Harris (2004) and those who see the role of nowadays university mainly linked to Humboldt teaching and research orientations so nonsupportive entrepreneurial role of faculty members Slaughter and Leslie (2001). However, this is a simplistic view when it comes to managing a wider diversity of the key individuals when it comes to create more knowledge- and technology-based value for the surrounding society. The key question pretended in studies by Siegfried, Sanderson and McHenry (2007) intended to measure the economic impact of colleges and Universities and to show how much better off are area residents with the colleges and universities there.

Since the seminal studies of Etzkowits and Leydessdorff $(1996,2000)$ on the triplehelix model for innovation-based value creation, universities across the world have leapt at the opportunity of raising more funds from contracts with the surrounding business system and the support of the public sector. This paradigm is rooted in the Mode- 2 of knowledge production (Gibbons et al., 1994) that implies that the new knowledge is obtained by closely collaborating between creators and users, while in the Mode-1 knowledge is first created by research units and then someone is in charge of seeking possible applications. That paradigm has lead scholars in the field of academic entrepreneurship to debate whether there is an isomorphic trajectory of developing an entrepreneurial university regardless the context where the university locates. Tuunainen (2005) has criticized the hybrid practices that Etzkowitz (2003) had claimed as a global trend. While Etzkowitz et al.'s (2000) have posited that universities willing to become more entrepreneurial follow an isomorphic trajectory that takes the form of hybrid practices of knowledge creation, Tuunainen (2005) has claimed that the phenomenon is more complex and universities actually adapt their portfolio to the local agendas in terms of teaching, researching and transfer of knowledge (Audretsch ,2014.) This means that, rather a unique global trajectory, universities develop specific combinations of the three core activities depending upon local contexts. However, the success of that deployment depends on how faculty members, the key human factor in universities, behave. Philpott et al. (2014) also criticized the possibility that an isomorphic solution may exist since the ideal of an entrepreneurial university is context- 
dependent. They have informed about the underlying tensions among supporters and non-supporters. As they describe, those tensions are rooted in the need for managing expectations regarding the third mission of the university.

Despite the inexistence of a unique definition of what an entrepreneurial university means, the notion can be summarized as the managerial process that research groups undertake when developing their usual research projects, namely raising funds, transfer of results, financing internally their needs of capital for future activities and the like (for definitions see Clark, 1998; Sporn, 2001, Etzkowtiz, 2004; or Kirby, 2006, as well as Yusof and Jain's analysis, 2010). In the European context, the debate of what the role of a university should be in the modern society is even more heated since the origins of the oldest universities date back to 500 years ago. This adds inertial forces against this process of change from Mode-1 to Mode- 2 of knowledge production.

In this context, scholars in the field of academic entrepreneurship have usually studied the faculty members' attitudes relative to the entrepreneurial university in terms of supportive and non-supportive individuals (e.g. Martinelli et al., 2008; Todorovic et al., 2014). Or put it differently, whether a faculty member has or has not an entrepreneurial orientation when developing his/her academic duties and how this attitude predicts one's involvement in transfer of knowledge or technology. This is a rather simplistic viewpoint of the complexity underlying the management of human factor in medium and large organizations. Lacetera (2009) suggested the existence of different types of faculty member attitudes in the commercialization of results when compared to industrial scientists. From studies in the field of organizational performance we know that entrepreneurial orientation and heterogeneity of the team have an impact on achieving positive results in the process of innovating (Van Doorn et al., 2013). Nevertheless these authors found that the CEO's heterogeneity play a moderating role in that relationship. We can extend this finding and suggest that individuals groups are heterogeneous and this characteristic should be considered in any study including individual's attitudes. Therefore, there is a need for digging deeper in the classification of the faculty members when it comes to their attitude regarding the entrepreneurial university. 
On reviewing the increasing literature on this topic of entrepreneurial university, the essence of the debate seems to have been diluted in the empirical results rather than providing implications for the theory.

A very comprehensive study on the taxonomy and concepts about the entrepreneurial university were researched by Rothaermel et al. (2007) in a content analysis of 173 articles around university entrepreneurship. They found four main research streams: the entrepreneurial university (50\% of the analyzed papers), new firm creation (24\%), environmental context (17\%), and productivity of technology transfer offices (9\%). The boundaries of the entrepreneurial university topic are necessarily blurred with relevant contributions from other fields, such as entrepreneurship, knowledge production, and organizational management, as suggested by Yusof and Jain (2010). Those authors claimed that university-level entrepreneurship comprises three different although intertwined fields: the entrepreneurial university, university technology transfer, and academic entrepreneurship.

These viewpoints depend highly on the lens used to analyze the phenomenon: the process of change and strategic management within large and ancient institutions like universities, a change mainly requested by the local stakeholders wherein the university acts, namely enterprises, public sector and society, be this context the triple-helix model of Etzkowitz and Leydesdorff (2000) or the Gibbon and collaborators' Mode-2 of knowledge production (Gibbons et al., 1994).

The entrepreneurial university deals with the path trajectory that a university takes in order to be a factor for economic progress and development in today's economy. Hence it deals with a strategic perspective of what a university is for, being the key proponents authors like Etzkowitz (1983; 1989), Clark, (1998), Kirby (2006) or Sporn (2001).

University technology transfer deals with the role of the university in the system of innovation, as one but not the only source of economic progress. Here, key proponents are Jensen and Thursby (2001), Thursby and Thursby (2002), Powers and McDougall (2005), or O'Shea et al. (2005).

Academic entrepreneurship is related to the key results of a combination of the three missions of the university, focused mainly on entrepreneurship results. In this case, keyproponents are Louis et al. (1989, 2001), or Chrisman et al. (1995). 
If we see the latter three research streams as a portfolio of possible different combinations that a university can manage, then we will clearly realize the sources of tensions derived from that combination. Philpott et al. (2011) analyzed these tensions from two approaches: the management of academic entrepreneurship in top-down (closer to the traditional paradigm) and bottom-up modes (closer to entrepreneurial paradigm). They claim that the main issue arises when the university tries to enhance the third mission while maintaining traditional higher education and research, when the clash among the three missions may arise more intensely. Rasmussen (2008) had already highlighted the success of the Canadian and US efforts to commercialize their universities' research from a bottom-up approach, while Goldfarb and Henrekson (2003) pointed out the failure of the top-down approach in a Swedish case. Similarly, Philpott et al. (2011) found that a high level of top-down push about becoming an entrepreneurial university will have the effect of reducing the entire entrepreneurial activity of the whole university.

Technology transfer also generates increasing problems within the university if not properly managed. Bercovitz and Feldman (2008) as well as Thursby and Thursby (2002) highlighted some of the reasons why faculty members would decide not to get engaged in this type of activity: mainly the lack of motivation of the researchers specializing in basic research activities and their negative attitudes. The scientist's career cycle shows how he or she seeks to build a reputation in hisher field in the early stages, while in later stages they search mostly for aneconomic return (Stephan and Levin, 2001). Thursby and Thursby (2002) also pointed out that some basic research scientists consider commercial activity as inappropriate for their career. Hence the faculty members' attitudes are one of the key challenges that university managers must face in the transition towards a more entrepreneurial university.

We believe that both modes can take place simultaneously, because both exchanges and research are usually conducted at either individual or research group levels rather than at the institutional level, even though a transfer unit may exist within the university. The role of individuals is clearly addressed, for instance, in the case of technology transfer research, as noted above Dabic and Svarc (2011). Therefore, Mode-2 cannot exist without Mode-1 but can take place simultaneously, as individuals within the same university can choose freely either one or the other approach, without being an exclusive choice. Actually, one complements each other. 
Etzkowitz (2003) and Kirby (2006) showed clearly how some of the leading research universities are among the most successful entrepreneurially. Hence the goals can be considered as complementary instead of substitutive and irreconcilable. They asserted that researchers are the ones who really transfer, research, and teach, motivated by their particular objectives. Hence, the individual level seems to be what really matters to understand and what can explain the hybrid practices and the dynamics of entrepreneurial university theory and practice.

A similar incorrect logic could be being applied to the individual level when speaking about the three missions of the university. This means that the three missions must be developed by the collective of academic and administrative staff although each individual must not necessarily undertake tasks related to all three missions. What we imply as incorrect logic is the assertion that some universities are research-oriented while others are applied-oriented, as if a university (its researchers) cannot undertake both simultaneously. Furthermore, Boardman and Ponomariov (2009) found that the "traditional scientific values" -in terms of research not necessarily conducted for obtaining an economic return- are not relevant and have no negative effect on industry collaboration. Thus, the debate on research-oriented versus entrepreneurial university is not so relevant, at least if we think of this at an individual rather than an institutional level. The teaching dimension is clearly assumed in higher education institutions and among the academic staff. However, the presumable clash between research and transfer goals may well stem from contradictions in the reward system (Bercovitz and Feldman, 2006; Philpott et al., 2011).

This calls for a specialization rooted in the managerialism principles under the possibility of either segregation or integration of research and transfer activities in different organizational units (Etzkowitz, 2003), perhaps within a faculty and under a coordination unit for the whole university. Then it follows that at the individual level, faculty members could specialize in some but not undertake all the activities (teaching, research, transfer), what would entail the need for managing the portfolio of activities teaching, research and transfer- at organizational levels (i.e. not only university but within the faculties as well). The key question would be how to promote this kind of specialization, if possible. 
Therefore, we must first uncover a full understanding of the attitudes that supportive faculty members have relative to their entrepreneurial orientation in the paradigm of the entrepreneurial university.

We must mention that this is still an emerging research domain and thus we need to conduct exploratory research and discuss some general principles before trying to establish any theory, be this an isomorphic trajectory or not. Tuunainen (2005) categorized the models of transformation in science and universities in two wide streams: those claiming radical transformation and those claiming a moderate transition. Nevertheless, it seems that this is not a question of whether a radical or a moderate transition is the best way, because a great deal of relevant changes in large organizations is undertaken slowly due to inertia. Then what we must research is how to accelerate this slow motion, by minimizing the key barriers in this type of change: attitudes. Boardman and Ponomariov (2009) also suggested this premise of substantial variation at the individual level in universities, because of university scientists are the ones who really govern the interactions with firms.

The non-isomorphism of the transitional trajectories, noted by Tuunainen (2005) as a critique to the Etzkowitzanian path and also partially questioned by Philpott et al. (2011), may be mainly due to an incorrect extension of individual-level concepts towards the full organization level. This is the misunderstanding of how to manage the university's portfolio in terms of education, research, and transfer, bottom up from the key actors of any change, the human capital.

Van Looy and colleagues (Van Looy et al., 2004; Van Looy, 2009; Van Looy et al., 2011) provided continuous and relevant examples of the non-existence of a trade-off between entrepreneurial and scientific activities, when conducted in an orderly way and with hybrid structures. They demonstrated this with the case of the KU Leuven (Belgium) and other 105 European universities with a relevant development of a clear portfolio and the adaptation in the reward system: mostly a dual system, combining the research excellence typically along the hierarchical lines of faculties and departments with excellence in entrepreneurial innovation rewarded within the new division created 
(a unit only for Research and Development). In fact, they claimed the existence of a Matthew-effect in a virtuous spiral that feeds back both activities, each one reinforcing the positioning of the other. The Matthew-effect was originally described by Merton (1968), as the "rich get richer" when applied to the measurement of scientific production. But it also was subsequently reported by Merton (1998) in what regard the allocation of scientific resources.

Meanwhile, González-Loureiro and Pita-Castelo (2012) showed that the institutional system for supporting innovation, with particular attention to universities, seemed not to play the expected role in innovation-based growth in today's economy. Therefore, the linkages and ties with one of the main (but not the only) scientific knowledge creators can still be improved.

The relevance of the faculty members in reaching an ideal of the entrepreneurial university has been already highlighted by Philpott et al. (2011) and Todorovic et al. (2005, 2011). The latter found that a scale of faculty attitudes measuring their entrepreneurial orientation predicted the results of patents and spinouts at the department level. The former also researched professors' attitudes towards the entrepreneurial university, suggesting that two opposed groups exist: supportive and unsupportive professors. They concluded that the individual action is a condition needed but not sufficient for developing an entrepreneurial university. That means the need for an entrepreneurial unit for transfer in a wide sense but most of all it has implications that shared ethos and mindsets are required throughout the whole organization at the individual level as pre-existing condition. This emphasizes again that the human capital is the basic starting point for the shift. The importance of human capital is strongly associated with the attitudes of the university leadership; therefore, as Rasmussen et al. (2006) confirmed, the entrepreneurial activities are initiated and driven by a reduced group of motivated and dedicated researchers who are supported through a network.

The key issue is whether only those two opposed forces exist (supportive vs. unsupportive) within the university or whether the support is not a question of a 
dichotomist response but a graduation that crosses over several complex issues. This acquires a higher relevance if we consider that most universities usually need a relevant number of years prior to obtaining a positive return from its technology transfer activities, ranging from 5 to 10 years (Philpott et al., 2011) and up to 30 to 40 in the case of North Carolina's Research Triangle Park (Bercovitz and Feldman, 2008). Notwithstanding that the USA case may differ from other countries, as Rasmussen (2008) pointed out with his Canadian case, the reality shows that the transition depends highly on the attitudes adopted by the faculty. The faculty can be categorized into five types of inventors as noted by Livesay et al. (1996). Between these categories, the groups associated with entrepreneurial activities are "entrepreneurs with technology"

(who create and expand new technologies in the market) and "industry-specific inventors" (who create a technology for a special industry).

Briefly, the trajectory path seems to be anything but radical, and there is only one way for speeding up this process. Those universities facing a transitional trajectory must understand first the different types of human capital they have. Hence they can reduce some of the main sources of conflict more easily, and even take advantage of the different types of expertise. In the next sections we explain the empirical work conducted in the case study of a control group of Croatian and Spanish universities. Our aim was to test our unique working hypothesis, as follows:

Hypothesis: Among those faculty members who claim to support the concept of a more entrepreneurial university, there are different groups of individuals in terms of attitudes.

\section{RESEARCH METHODOLOGY AND RESULTS}

We conducted a survey among a sample in Croatian and Spanish universities. The approach is similar to the procedures described by Creswell (1994) and also followed by Todorovic et al. (2011). Because we were using a case study, we decided to conduct the test in two fairly different scenarios, Croatia and Spain. This method will reinforce our findings on what was common while disclosing what was context-dependent. Table 1 
shows the differences in the key characteristics of the higher education institutions (HEI) in those two scenarios.

The differences are quite clear, particularly in the case of the average number of faculty and students per institution: the Spanish university shows the higher figures. Nevertheless, the average number of students per faculty member is quite similar. That would mean that the effort devoted to educational obligations is fairly similar. Hence the academic staff would have a similar number of working hours for other activities like research and transfer.

However, in terms of results, the figures are quite different. Croatia has higher figures in both resident patent applications per \$Billion of GDP and resident patent filings per \$Million of R\&D expenditures, doubling the Spanish figures. Conversely, Spain produces almost twice the scientific and journal articles per HEI academic staff members. This would mean that the Croatian HEI would be more entrepreneurial than the Spanish, hence two quite different cases to be analyzed.

Table 1

Key Figures of Higher Education Institutions in Croatia and Spain (2009)

\begin{tabular}{lcc}
\hline \multicolumn{1}{c}{ COUNTRY } & Croatia & Spain \\
\hline Number of HEInstitutions (2009) & 54 & 79 \\
Number of students 2009 (ISCE levels 5-6) & 139,069 & $1,800,834$ \\
Number of faculty members 2009 & 13,866 & 151,598 \\
Average of students per institution & 2,575 & 22,795 \\
Average of faculty members per institution & 256.78 & $1,918.96$ \\
Average of students per faculty members & 10.03 & 11.88 \\
Resident patent applications per \$Billion GDP (*) & 6.06 & 3.08 \\
Resident patent filings per \$Million R\&D Expenditures (*) & 0.56 & 0.31 \\
Researchers in R\&D (per million people) (*) & 1,571 & 2,932 \\
R\&D expenditure (\% of GDP) (*) & 0.83 & 1.38 \\
Scientific and journal articles (*) & 1,164 & 21,543 \\
Average number of scientific and journal articles per total number of & 0.08 & 0.14 \\
academic staff at HEInstitutions
\end{tabular}

Source: Authors' derivation from Eurostat data, except (*) WIPO Statistics Database, World Bank (World Development Indicators) 
We conducted a survey among a sample of faculty members belonging to Croatian and Spanish universities between March and July 2011. The survey method was a downloadable survey sent by a link to the email of the heads of departments and to the vice-chancellors of research and/or transfer in each university.

The final sample was an equally distributed sample between both Croatian and Spanish universities, with 90 supportive professors each. We controlled that they were supportive with a first eliminatory question. In terms of departments and type of positions, the sample is quite balanced, as we were seeking a group that was representative of an average HEI of each country. Among the individuals of the sample there are $20.7 \%$ of full-time professors, $21.8 \%$ of assistant professors, $18.4 \%$ of associate professors, and the rest are other tenured positions (such as lecturers). The surveyed individuals average a mean of 9.8 years in their current position, with $40.5 \%$ who had occupied his or her current position for more than 10 years, $20.2 \%$ for 5 to 10 years, and $39.3 \%$ for fewer than 5 years. A balanced characteristic of the sample is that $51 \%$ had private sector experience and $49 \%$ had been awarded with a national scientific project in the previous 5 years. These figures show that the sample is balanced well between experienced in both private and university sectors, as well as between a more scientific profile and more transfer-oriented individuals. T-tests for means differences were conducted in each variable. We found no evidence of difference statistically significant due to country or position. Statistical procedures for factor analysis and subsequent cluster analysis

We undertook a two-stepwise statistical procedure. An initial factor analysis was conducted to find which factors best grouped the 47 variables; then we saved the factor loadings into new variables. Subsequently, we developed a cluster analysis to find out how many different groups of cases existed, if any.

Participants were asked to assess that set of variables using a Likert scale ( $1=$ strongly disagree; $7=$ strongly agree), following the work of Todorovic et al.. Reverse coded variables were used where appropriate to avoid routine responses (they are noted in the appendix).

Following Creswell (1994), we conducted a wave analysis to evaluate the possibility of non-response bias of the earliest and the latest for all the variables (two tails of $25 \%$ each). In no case were the means significantly different at $\mathrm{p}=0.05$; hence, we assumed that both early and late respondents belonged to the same population. No missing data 
were noticed. Additionally, a random selection of $20 \%$ of respondents were contacted telephonically to check their answers and hence assure the quality of the data..

An initial analysis of correlations among the 47 variables was conducted with SPSS (v. 15.0). Corrected item-total correlations were calculated. Initially, the items with at least 0.5 item-total correlations were selected. A bivariate correlations matrix was checked to assure that none was in excess of 0.9 , thus avoiding a possible problem of multi-colinearity. In this case, 18 items were retained. These items group into four factors of attitudes best, by using a method of principal component analysis and a Varimax rotation with Kaiser normalization: department reputation-orientation, industry collaboration, unconventionality, and university policies. Names of the factors are designed according to extracted communalities of the variables, following the methodology of Todorovic et al. (2011), as shown in Table 2.

We must mention that main changes in factors, when compared with the above mentioned work, are the inclusion of "department reputation-orientation" in our case, while we did not include their "research mobilization." factor As they explained, their "research mobilization" factor included six items related to research involving external partners in research. This is not our case. In our factor labeled as F1 "department reputation-orientation," the items are highly related to how the industry assesses the department as a whole, particularly when compared with other departments. The "reputation" label suited our case better than "research mobilization" although we shared the idea that "knowledge mobilization" is underlying in both cases. In their case, two key items were related to how the department encourages students to engage in research-industry activities with practical implications. In our case, key items are related to recognition and reputation. Hence, the differences are semantic nuances.

All the reliability measures confirmed the validity and convergence of each construct, as usual. It is noteworthy to mention that Todorovic et al. (2011) used a Promax rotation method with Kaiser normalization because they needed an oblique rotation to allow factors to share variance and to finally develop a regression that best explained an outcome (results in patents and spinouts). This was not our case. Our aim was not a regression but to find out whether different types of cases existed. Therefore, an orthogonal rotation was more suitable for detecting and best explaining the cluster of cases with efficiency in the number of factors used (parsimony). Therefore, we decided to use a Varimax rotation with Kaiser normalization. 
Table 2

Final Variables Included in Each Factor from Attitudes Scale

\begin{tabular}{|c|c|c|}
\hline $\begin{array}{l}\text { FACTOR AND RELIABILITY } \\
\text { INDICATORS }\end{array}$ & $\begin{array}{l}\text { Extracted } \\
\text { Communa- } \\
\text { lities }\end{array}$ & Final Variables Included \\
\hline \multirow{5}{*}{$\begin{array}{l}\text { F1: } \\
\text { DEPARTMENT ORIENTATION } \\
\text { REPUTATION } \\
\text { Conbrach's alpha: } 0.920 \\
\text { Total variance explained: } 75,83 \% \\
\text { Kaiser-Meyer-Olkin index: } 0.838 \\
\text { Bartlet's test of sphericity: } 321.86 \\
(\text { p }<0.000)\end{array}$} & 0.842 & DRO1. Our department is highly regarded by industry \\
\hline & 0.767 & DRO2. We are recognized by industry or society for our flexibility and innovativeness \\
\hline & 0.760 & $\begin{array}{l}\text { DRO3. Compared to other similar departments in our province, our department has a } \\
\text { reputation for its contribution to industry or society }\end{array}$ \\
\hline & 0.714 & DRO4.Our graduate students often secure high-quality industry positions \\
\hline & 0.709 & $\begin{array}{l}\text { DRO5. Compared to other similar departments in this province, we are good at } \\
\text { identifying new opportunities }\end{array}$ \\
\hline \multirow{5}{*}{$\begin{array}{l}\text { F2: } \\
\text { INDUSTRY COLLABORATION } \\
\text { Conbrach's alpha: } 0.899 \\
\text { Total variance explained: } 71.25 \% \\
\text { Kaiser-Meyer-Olkin index: } 0.882 \\
\text { Bartlet's test of sphericity: } 245.27 \\
(p<0.000)\end{array}$} & 0.771 & $\begin{array}{l}\text { IC1. We encourage industry involvement in the research activities of our faculty } \\
\text { members }\end{array}$ \\
\hline & 0.734 & IC2. We support our faculty members collaborating with non-academic professionals \\
\hline & 0.703 & $\begin{array}{l}\text { IC3. Our faculty members often seek research opportunities outside the traditional } \\
\text { university environment }\end{array}$ \\
\hline & 0.702 & IC4. We try to generate off-campus benefits from research projects \\
\hline & 0.652 & $\begin{array}{l}\text { IC5. Many of our faculty members conduct research in partnership with non-academic } \\
\text { professionals }\end{array}$ \\
\hline \multirow{4}{*}{$\begin{array}{l}\text { F3: } \\
\text { UNCONVENTIONALITY } \\
\text { Conbrach's alpha: } 0.842 \\
\text { Total variance explained: } 68.14 \% \\
\text { Kaiser-Meyer-Olkin index: } 0.792 \\
\text { Bartlet's test of sphericity }(137.21 \\
\text { (p<0.000) }\end{array}$} & 0.701 & UC1. Our department encourages "thinking outside the box" even at the risk of failure \\
\hline & 0.692 & $\begin{array}{l}\text { UC2. Our faculty members are willing to take unconventional approaches when } \\
\text { working on research problems }\end{array}$ \\
\hline & 0.667 & $\begin{array}{l}\text { UC3. Compared to other similar departments in this province, we act quickly in } \\
\text { response to new opportunities }\end{array}$ \\
\hline & 0.666 & $\begin{array}{l}\text { UC4. We are often the first to introduce new methods of teaching, courses, or degrees } \\
\text { that other universities subsequently adopt }\end{array}$ \\
\hline \multirow{4}{*}{$\begin{array}{l}\text { F4: } \\
\text { UNIVERSITY POLICIES } \\
\text { Conbrach's alpha: } 0.880 \\
\text { Total variance explained: } \mathbf{7 3 . 7 2 \%} \\
\text { Kaiser-Meyer-Olkin index: } 0.833 \\
\text { Bartlet's test of sphericity: } \mathbf{1 8 2 . 6 2} \\
\text { (p<0.000) } \\
\end{array}$} & 0.779 & $\begin{array}{l}\text { UP1. We feel that university-wide policies at this university contribute substantially } \\
\text { towards our department achieving its goals and objectives }\end{array}$ \\
\hline & 0.773 & $\begin{array}{l}\text { UP2. Our university policies are best described as developed "bottom-up" using } \\
\text { feedback from all levels of the university }\end{array}$ \\
\hline & 0.769 & $\begin{array}{l}\text { UP3. Compared to most other universities, our university is very responsive to new } \\
\text { ideas and innovative approaches }\end{array}$ \\
\hline & 0.627 & UP4. Our university rewards faculty members for their entrepreneurial attempts \\
\hline
\end{tabular}

Extraction method: Principal component analysis, Varimax rotation with Kaiser normalization

Once we had saved the scores for each factor, we conducted a principal component analysis to find out whether different groups of professors (cases) existed. Eigenvalues above 1.0 showed the possible existence of three different types of cases. Common tests were developed to assure their validity. The Wilks' Lambda tests the equality of group means. The values obtained by each group for each of the four constructs allow us to confirm the validity of the mean within the group. The Box tests of equality of covariance matrices contrast the null hypothesis of equal population covariance matrices in the three clusters of cases. The test rejected the null hypothesis ( $\mathrm{p}$-value $=0.268)$; therefore, covariance matrices are different for each cluster and we can accept that they comprise different types of attitudes regarding their entrepreneurial orientation. 
The procedure extracted two canonical discriminant functions. The first cumulated $83 \%$ of the variances while the second cumulated 17\%. Using Fisher's linear discriminant functions, the first cluster contains 24 cases, the second contains 37, and the third has 27. These data show the balanced number of cases in each cluster and hence the validity of the method to cluster different types of attitudes.

Figure 1 shows the result of the classification procedure, where the function coefficients obtained from a Fisher's linear discriminant function are shown. It also depicts the two canonical discriminant functions with centroids for each cluster and the distribution of the points belonging to each of the three clusters. The cluster 1 centroid acquires the lowest values in both functions. The cluster 3 centroid has a negative value for function 1 and a positive one for function 2. Conversely, the cluster 2 centroid has negative values for function 2 and positive for function 1 . In fact, only cluster 2 has positive values for function 1 .

Figure 1.

Canonical Discriminant Functions

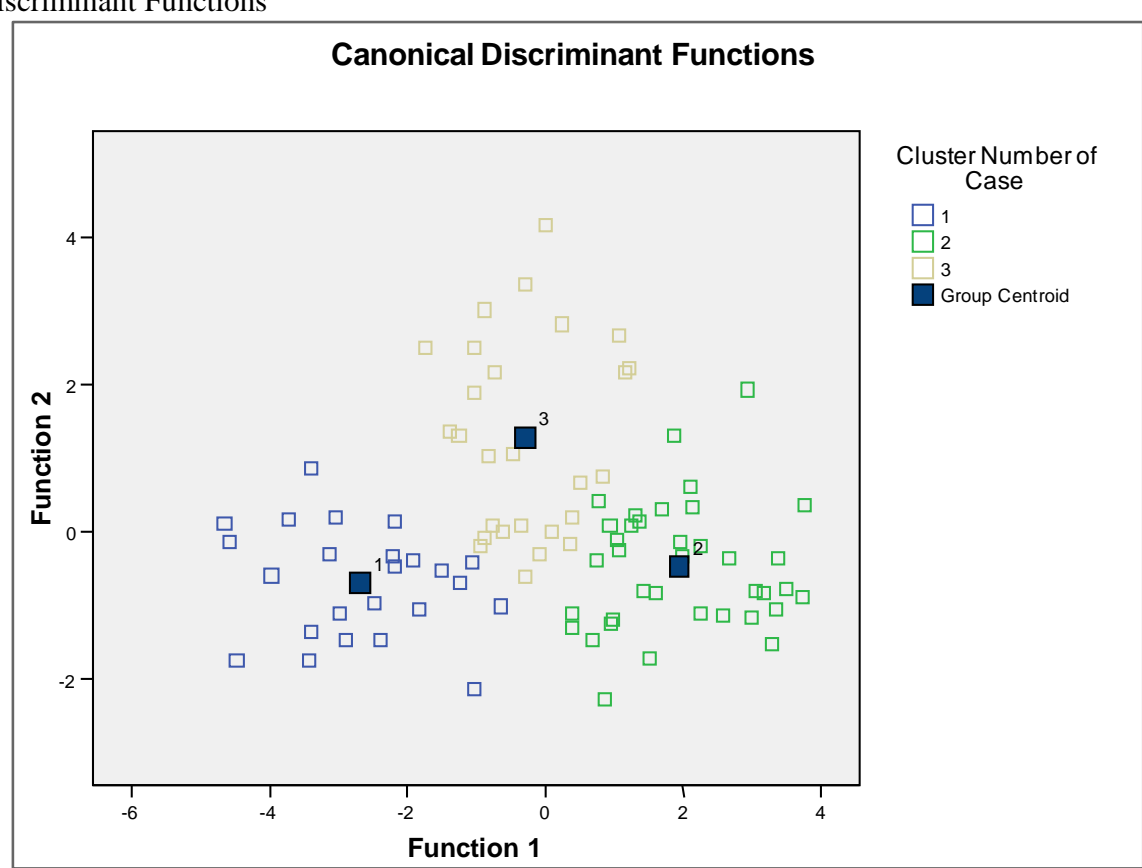

Classification: Function Coefficients 


\begin{tabular}{l|c|c|c}
\multicolumn{1}{c|}{ FACTOR } & Cluster 1 & Cluster 2 & Cluster 3 \\
\hline $\begin{array}{l}\text { F1: Department orientation } \\
\text { reputation }\end{array}$ & -2.197 & 1.601 & -0.241 \\
\hline F2: Industry collaboration & -1.348 & 0.155 & 0.986 \\
\hline F3: Unconventionality & -1.864 & 0.928 & 0.384 \\
\hline F4: University policies & -1.757 & 2.541 & -1.921 \\
\hline \multicolumn{1}{c}{ Constant } & -5.122 & -2.872 & -2.038 \\
\hline
\end{tabular}

Using Fisher's linear discriminant functions

Additionally, a Kruskall-Wallis' test was developed to assure the existence of mean differences among the three clusters. The asymptotical significance of the chi square confirms the validity of the three clusters, because the variables used to measure attitudes obtained a p-value below 0.000 on the test.

With these values, it is clear there are three different types of attitudes towards entrepreneurial orientation in this sample of Croatian and Spanish university staff. That means that different perceptions of the reality coexist in the same institution. We have also used a Kruskall-Wallis' test to evaluate the possible existence of differences due to control variables such as country, faculty position, or private sector experience. In the two latter cases, the test offered no significant differences due to those control variables at an asymptotic significance level of 0.01 . In the case of country, only two small differences existed at an asymptotic significance level of $p=0.05$ but not at a $p=0.01$ level. One is related to the encouragement of industry involvement in the research activities of the faculty members (factor F2 industry collaboration). In this case, Spanish participants considered that there is a higher level of encouragement (mean of 4.66) while Croatian participants found it lower (mean of 3.80), with $\mathrm{p}=0.038$. The second small difference is related to how professors feel that university-wide policies contribute substantially towards their department's achieving its goals and objectives (factor F4 university support). Croatian professors thought that their university policies contributed more (mean of 4.27) than Spanish professors thought theirs did (mean of 3.45), with $\mathrm{p}=0.013$. As shown, these differences were small in intensity, while embracing the central point of 4 on a Likert-scale of 7.

Table 3 provides the breakdown by clusters (groups of professors according to their attitudes) for the means reached by the retained 18 variables grouped into 4 factors: department orientation, industry collaboration, unconventionality, and university 
policies. This led us to accept our unique hypothesis (H1): professors' attitudes toward the entrepreneurial orientation are not the same among those who claim to support the concept of a more entrepreneurial university.

Table 3.

Attitude Means for Each Group of Professors

\begin{tabular}{|c|c|c|c|c|}
\hline FACTORS & |VARIABLES & $\begin{array}{l}\text { cluster } 1 \\
\text { MEAN }\end{array}$ & $\begin{array}{l}\text { cluster } 2 \\
\text { MEAN }\end{array}$ & $\begin{array}{l}\text { cluster } 3 \\
\text { MEAN }\end{array}$ \\
\hline \multirow{5}{*}{$\begin{array}{l}\text { Factor 1: } \\
\text { Department } \\
\text { orientation } \\
\text { reputation }\end{array}$} & DRO1. Our department is highly regarded by industry & 2.08 & 5.08 & 4.44 \\
\hline & $\begin{array}{l}\text { DRO2. We are recognized by industry or society for our flexibility and } \\
\text { innovativeness }\end{array}$ & 2.25 & 4.86 & 4.04 \\
\hline & $\begin{array}{l}\text { DRO3. Compared to other similar departments in our province, our } \\
\text { department has a reputation for its contribution to industry or society }\end{array}$ & 2.83 & 5.27 & 5.07 \\
\hline & DRO4. Our graduate students often secure high-quality industry positions & 2.46 & 4.95 & 4.11 \\
\hline & $\begin{array}{l}\text { DRO5. Compared to other similar departments in this province, we are } \\
\text { good at identifying new opportunities }\end{array}$ & 3.00 & 5.51 & 4.78 \\
\hline \multirow{5}{*}{$\begin{array}{l}\text { Factor 2: } \\
\text { Industry } \\
\text { collaboration }\end{array}$} & $\begin{array}{l}\text { IC1. We encourage industry involvement in the research activities of our } \\
\text { faculty members }\end{array}$ & 2.08 & 5.14 & 5.00 \\
\hline & $\begin{array}{l}\text { IC2. We support our faculty members collaborating with non-academic } \\
\text { professionals }\end{array}$ & 3.13 & 5.68 & 5.44 \\
\hline & $\begin{array}{l}\text { IC3. Our faculty members often seek research opportunities outside the } \\
\text { traditional university environment }\end{array}$ & 2.58 & 5.24 & 5.41 \\
\hline & IC4. We try to generate off-campus benefits from research projects & 2.92 & 5.57 & 5.04 \\
\hline & $\begin{array}{l}\text { IC5. Many of our faculty members conduct research in partnership with } \\
\text { non-academic professionals }\end{array}$ & 2.33 & 4.92 & 4.07 \\
\hline \multirow{4}{*}{$\begin{array}{l}\text { Factor 3: } \\
\text { Uncon- } \\
\text { ventionality }\end{array}$} & $\begin{array}{l}\text { UC1. Our department encourages "thinking outside the box" even at the } \\
\text { risk of failure }\end{array}$ & 2.38 & 4.65 & 3.89 \\
\hline & $\begin{array}{l}\text { UC2. Our faculty members are willing to take unconventional approaches } \\
\text { when working on research problems }\end{array}$ & 2.96 & 5.03 & 4.89 \\
\hline & $\begin{array}{l}\text { UC4. We are often the first to introduce new methods of teaching, courses, } \\
\text { or degrees that other universities subsequently adopt }\end{array}$ & 2.88 & 4.97 & 3.95 \\
\hline & $\begin{array}{l}\text { UC5. Compared to other similar departments in this province, we act } \\
\text { quickly in response to new opportunities }\end{array}$ & 2.63 & 4.68 & 4.44 \\
\hline \multirow{4}{*}{$\begin{array}{l}\text { Factor 4: } \\
\text { University } \\
\text { policies }\end{array}$} & $\begin{array}{l}\text { UP1. We feel that university-wide policies at this university contribute } \\
\text { substantially towards our department achieving its goals and objectives }\end{array}$ & 2.96 & 5.24 & 2.67 \\
\hline & $\begin{array}{l}\text { UP2. Our university policies are best described as developed "bottom-up" } \\
\text { using feedback from all levels of the university }\end{array}$ & 2.71 & 4.46 & 2.52 \\
\hline & $\begin{array}{l}\text { UP3. Compared to most other universities, our university is very } \\
\text { responsive to new ideas and innovative approaches }\end{array}$ & 3.04 & 5.49 & 3.22 \\
\hline & $\begin{array}{l}\text { UP4. Our university rewards faculty members for their entrepreneurial } \\
\text { attempts }\end{array}$ & 2.21 & 4.54 & 2.37 \\
\hline
\end{tabular}

Likert scale: $1=$ strongly disagree; $7=$ strongly agree

After reaching these results, we conducted interviews to validate the groups' profiles, which allowed us to validate the background and characterization of each cluster.

Professors in Cluster 1 are characterized by a relevant negative perception of the current entrepreneurial orientation of their university. They feel their department has a very low degree of entrepreneurial orientation (the lowest of the three groups). They also think there is a lack of industry collaboration, while the university policies do not seem to help at all. Despite this, they believe that there is too much conventionality in their 
institution. All these values seem to point to a more than possible dissatisfaction among them. While they really support the idea of an entrepreneurial university, those unsatisfied expectations may lead them to potential conflicts. In fact, the lowest value (2.08) is given to the lack of the university encouraging industry involvement in research. If one thinks an imbalanced relationship exists, then it is very likely he / she will start searching for ways to obtain what he or she deserves, leaving the organization because it does not contribute. We called these as "unsatisfied-disaffected professors" since they support the entrepreneurial university concept but they conferred the lowest values to every item (all of them below the neutral point of 4 on the Likert scale of 7).

On the opposite side, the professors categorized in Cluster 2 assessed each item with the highest values. They thought their department had a good entrepreneurial orientation. They also considered their university as sufficiently supportive of their activities. They reported engaging with industry collaboration in their activities, and they are the professors who most seek unconventional ways for addressing the work. As this kind of work is usually undertaken in working groups, we called them "team-working professors." They seem to think more in terms of the group instead of individually, maybe because the individual goals are aligned with the group as well as the department. Perhaps they are the professors who prove to have the most entrepreneurial attitudes with a clear idea of how things must be done to achieve the best performance, according to the known game rules. These results are congruent with the findings of Hoye and Pries (2009), who concluded that researchers with technology transfer experience are a group with a non-traditional view of the academy when compared with those not involved in technology transfer.

Finally, the Cluster 3 group seems to be the two faces of a coin. On the one hand, their assessment of department orientation and industry collaboration items are not high although very close to Cluster-2 values. For instance, they felt the department orientation was not sufficient, very close to a neutral value (4), i.e., still improvable. On the other hand, unconventionality items pointed out that some kind of problem may exist in finding alternative ways according to the known game rules. And this is very likely caused by the lack of university support they feel, because every value here (F4 university policies) is at 3.6 (on a scale from 1 to 7 ). Special attention must be drawn to the reward system because, in the opinion of these professors, it does not encourage 
entrepreneurial attempts. Governance should be also reviewed, according to this cluster, because top-down policies are not the most suited for an entrepreneurial orientation.

\section{DISCUSSION}

The research question addressed here is whether different groups of attitudes exist among the faculty who claim to support the idea of a more entrepreneurial university. Under the approach of the attitudinal scale developed and tested by Todorovic et al. (2005, 2011) we provide evidence that at least there are three different groups of attitudes. Knowing the characteristics of these three groups and then involving the fourth group (the non-supportive), transitional universities can more properly manage the dilemma between separation versus integration (Etzkowitz, 2003). This might lead universities to some kind of specialization in order to play their expected and needed role in the regional system of innovation, following the premises of the triple-helix model (Etzkowitz and Leydesdorff, 1996, 2000; Etzkowitz et al., 2000).

We have also proved the validity of the Entre-U scale developed by Todorovic et al. $(2005,2011)$ for the purpose of categorizing different types of groups among supportive individuals.

Our evidence brings to the fore the suggestions of Philpott et al. (2011) concerning the existence of several different types of attitudes towards the entrepreneurial university. Additionally, as those authors addressed in their discussion, some tensions can emerge in the transition toward the entrepreneurial university paradigm.

In the debate about whether an isomorphic development path best suits this transition, our findings suggest that the three key gears of supportive professors is not contextdependent, bearing in mind that our case study addressed two quite different scenarios, universities in Croatia and Spain. The fact that these two scenarios are two different context but the faculty members shared similar attitudes, both reinforces our findings: there is a chance for some type of isomorphism if further studies also find these three types of supporters. 
The challenges that both theory and practice must face are related to the understanding of the specialization roles and portfolio management, at both the individual and organizational levels. Socioeconomic development calls for a university that must efficiently undertake activities related to higher education, research, and transfer. Therefore, university governance in the entrepreneurial paradigm is a question of achieving a relevant reputation among the university's external stakeholders, being involved in more industry collaboration, searching for unconventional ways to solve problems that arise over the process, and, last but not least, adapting its policies.

In this latter case, the key questions are related to the alignment of objectives among the different units (university, department, individual), a bottom-up approach and the reward system. Some of these questions were also noted by Philpott et al. (2011) that, in the case of reward systems, are usually key barriers. They suggested that, for instance, concentration on metrics such as patents and licenses cannot be effective because they convey counterproductive messages to faculty. This could be true if we consider the reward system as only applying to individuals. Our findings argue that the reward system, like other managerial tools, can no longer be understood as only individual but also as group incentives in order to manage the university portfolio properly at organizational levels. A portfolio of capabilities that, we believe, must be balanced among the three missions demanded by the today's socioeconomic agents to the university.

Future research from the human resource development and human resource management fields may provide a convenient adaptation to deal properly with the challenge of specialization. Further research is also needed for addressing the main limitation of the sample size of our case study as well as exploring the likely existence of these three groups of supportive individuals in universities all over Europe and the world.

The research results show that technology and society are inseparable in the context of university entrepreneurship. It is not just about technology, but also about the perceptions of the faculty members.

The attitude of researchers in universities has an interactive and dynamic dimension. For instance, those who succeeded in the commercialization of results keep on succeeding along the time (Gurdon and Samsom, 2010). Therefore, future research should conduct longitudinal studies, as well as further research should be undertaken to 
find out the context in which some faculty members may cross to a different group of attitudes.

Our findings point out the possible validity of an isomorphic path understood as a collective portfolio, following the argument provided by Philpott et al. (2011). Under different contexts, as the cases of Croatia and Spain show, the only possibility of difference is related to how to speed the transition based on the attitudes of the human capital. The point does not seem to be that the majority of entrepreneurial activities should gravitate towards the mid-point as they claim, to which we agree. The question is that transition should not mean the imbalance of the three missions, but rather taking advantage of the strengths that each group provide while governing the portfolio at the university level. That means trying to manage efficiently and effectively the three gears of supportive faculty while trying to involve the non-supportive faculty in the bottomup process of building the entrepreneurial university of tomorrow.

\section{References}

Altmann, A. and Ebersberger, B., 2013. Universities in Change: Managing Higher Education Institutions in the Age of Globalization (Innovation, Technology, and Knowledge Management), Springer;

Audretsch, D., 2014. From the entrepreneurial university to the university for the entrepreneurial society, The Journal of Technology Transfer, Vol 39.iss:3 pp. 313321

Bercovitz J. and Feldman M. , 2006. Entrepreneurial Universities and Technology Transfer: A Conceptual Framework for Understanding Knowledge-Based Economic Development. The Journal of Technology Transfer 31(1), 175-188.

Bercovitz J. and Feldman M. , 2008. Academic entrepreneurs: Organizational change at the individual level. Organization Science 19(1), 69-89.

Boardman P.C. and Ponomariov B.L., 2009. University researchers working with private companies. Technovation 29(2), 142-153.

Bok, D., 2003. Universities in the marketplace: The commercialization of higher education. Princeton, NJ: Princeton University Press.

Clark B.R. , 1998. Creating Entrepreneurial Universities: Organizational Pathways of Transformation. Issues in Higher Education. New York, NY, Elsevier Science Regional Sales. 
Clarysse, Wright, Lockett, Van de Velde, \& Vohora (2005) "Spinning Out New Ventures: A Typology of Incubation Strategies from European Research Institutions," Journal of Business Venturing

Covin J.G. and Covin T.J. , 1990. Competitive aggressiveness, environmental context, and small firm performance. Entrepreneurship Theory and Practice 14(4), 35-51.

Covin J.G. and Slevin D.P. , 1986. The development and testing of an organizationlevel entrepreneurship scale, in: Ronstadt R., Hornaday J.A., Peterson R., Vesper K.H. (Eds.) , Frontiers of Entrepreneurship Research. , Wellesley, Babson College, MA, pp. 628-639.

Covin J.G. and Slevin D.P. , 1989. Strategic management of small firms in hostile and benign environments. Strategic Management Journal 10(1), 75-88.

Creswell J.W. , 1994. Research Design: Qualitative and Quantitative Research Approaches. London, Thousand Oaks, CA: Sage Publications.

Chrisman J.J., Hynes T.,Fraser S. , 1995. Faculty entrepreneurship and economic development: The case of the University of Calgary. Journal of Business Venturing 10(4), 267-281.

Dabic, M. and Svarc , J., 2011. "About the Concept of Entrepreneurial University: Is There an Alternative?”, Društvena istraživanja, Vol. 20, No. 4, pp. 991-1013

Etzkowitz H. , 1983. Entrepreneurial scientists and entrepreneurial universities in American academic science. Minerva 21(2), 198-233.

Etzkowitz H. , 1989. Entrepreneurial science in the academy: A case of the transformation of norms. Social Problems 36(1), 14-29.

Etzkowitz H. , 1998. The norms of entrepreneurial science: cognitive effects of the new university-industry linkages. Research Policy 27(8), 823-833.

Etzkowitz H. , 2003. Research groups as 'quasi-firms': the invention of the entrepreneurial university. Research Policy 32(1), 109-121.

Etzkowitz, H., 2004. The evolution of the entrepreneurial university. International Journal of Technology and Globalisation 1(1), 64-77.

Etzkowitz H. and Leydesdorff L. , 1996. Emergence of a triple helix of universityindustry-government relations. Science and Public Policy 23, 279-286.

Etzkowitz H. and Leydesdorff L. , 2000. The dynamics of innovation: from National Systems and "Mode 2" to a Triple Helix of university-industry-government relations. Research Policy 29(2), 109-123.

Etzkowitz H., Webster A., Gebhardt C., Terra, B.R.C. , 2000. The future of the university and the university of the future: evolution of ivory tower to entrepreneurial paradigm. Research Policy 29(2), 313-330.

Guerrero, M., Cunnigham, J. and Urbano, D., 2015. Economic impact of entrepreneurial universities' activities: An exploratory study of the United Kingdom, Research policy,44. Pp. 748-764

Guerrero, M., Urbano, D., Cunnigham, J., Organ, D., 2014. Entrepreneurial universities: a case study comparison in two European regions. Journal of Technology Transfer 39 (3), 415-434. 
Gibb, A. A., 2012. 'Exploring the synergistic potential in entrepreneurial university development: towards the building of a strategic framework'. Annals of Innovation \& Entrepreneurship, 3: pp. 1-24

Gibbons M., Limoges C., Nowotny H., Schwartzman S., Scott P., Two M. , 1994. The New Production of Knowledge: The Dynamics of Science and Research in Contemporary Societies. London, Sage Publications Ltd.

Goldfarb B. and Henrekson M. , 2003. Bottom-up versus top-down policies towards the commercialization of university intellectual property. Research Policy 32(4), 639658.

González-Loureiro M. and Pita-Castelo J., 2012. A model for assessing the contribution of innovative SMEs to economic growth: The intangible approach. Economics Letters 116(3), 312-315.

Gurdon M.A., and Samsom K.J., 2010. A longitudinal study of success and failure among scientist-started ventures. Technovation 30, 207-214.

Philpott K., Dooley L., O'Reilly C., and Lupton G., 2011. The entrepreneurial university: Examining the underlying academic tensions. Technovation 31(4), 161170.

Harris, D. and Harris, F.J. 2004. "Evaluating the Transfer of Technology between Application Domians: A Critical Evaluation of the Human Component in the System." Technology in Society 26(4), 551-565

Harrison, R. 2010. "Voodoo Institution or Entrepreneurial University? Spin-off Companies, the Entrepreneurial System and Regional Development in the UK." Regional studies $44.9,1241-1262$.

Hoye K., and Pries F., 2009. 'Repeat commercializers,' the 'habitual entrepreneurs' of university-industry technology transfer. Technovation 29(10), 682-689.

Iacobucci, D. 2014. How to evaluate the impact of academic spin-offs on local development: an empirical analysis of the Italian case. The Journal of Technology Transfer, 01; 40(3).

Jensen R. and Thursby M. , 2001. Proofs and Prototypes for Sale: The Licensing of University Inventions. American Economic Review 91(1), 240-259.

Jansen, S., van de Zande T., Brinkkemper, S., Stam,W. and Varma, V.(2015) How education, stimulation, and incubation encourage student entrepreneurship: Observations from MIT, IIIT, and Utrecht University, The International Journal of Management Education 13 pp. 170-181

Khandwalla P.N., 1977. The Design of Organizations. New York, NY, Harcourt Brace Jovanovich, Inc.

Kirby D. 2006. Creating Entrepreneurial Universities in the UK: Applying Entrepreneurship Theory to Practice. The Journal of Technology Transfer 31(5), 599-603.

Lacetera N. 2009. Academic entrepreneurship. Managerial and Decision Economics 30(7), 443-464.

Livesay H.C., Lux D.S., and Brown M.A., 1996. Human factors and the innovation process. Technovation 16(4), 173-186,212. 
Louis K.S., Blumenthal D., Gluck M.E.,Stoto M.A. , 1989. Entrepreneurs in academe: An exploration of behaviors among life scientists. Administrative Science Quarterly 34(1), 110-131.

Louis K.S., Jones L.M., Anderson M.S., Blumenthal D.,Campbell E.G. , 2001. Entrepreneurship, secrecy, and productivity: A comparison of clinical and nonclinical life sciences faculty. The Journal of Technology Transfer 26(3), 233-245.

Martinelli A., Meyer M.,von Tunzelmann N. , 2008. Becoming an entrepreneurial university? A case study of knowledge exchange relationships and faculty attitudes in a medium-sized, research-oriented university. The Journal of Technology Transfer 33(3), 259-283.

Merton, R.K., 1968. The Matthew effect in science. the reward and communication systems of science considered, Science 159(3810), 56-63.

Merton, RK., 1988. The Matthew effect in science, II. Cumulative advantage and the symbolism of intellectual property, ISIS 79(4), 606-623

Miller D. , 1983. The correlates of entrepreneurship in three types of firms. Management Science 29(7), 770-791.

Miller D. and Friesen P.H. , 1978. Archetypes of strategy formulation. Management Science 24(9), 921-934.

O'Shea R.P., Allen T.J., Chevalier A.,Roche F. , 2005. Entrepreneurial orientation, technology transfer and spinoff performance of US universities. Research Policy 34(7), 994-1009.

Philpott K., Dooley L., O'Reilly C.,Lupton G. , 2011. The entrepreneurial university: Examining the underlying academic tensions. Technovation 31(4), 161-170.

Powers J.B. and McDougall P. , 2005. Policy orientation effects on performance with licensing to start-ups and small companies. Research Policy 34(7), 1028-1042.

Rasmussen E., Moen Ø., and Gulbrandsen M., 2006. Initiatives to promote commercialization of university knowledge. Technovation 26(4), 518-533.

Rasmussen E., 2008. Government instruments to support the commercialization of university research: Lessons from Canada. Technovation 28(8), 506-517.

Rothaermel F.T., Agung S.D. and Jiang L., 2007. University entrepreneurship: taxonomy of the literature. Industrial and Corporate Change 16(4), 691-791.

Slaughter S. and Leslie, L. L., 2001. Expanding and elaborating the concept of academic capitalism. Organization, 8(2), 154-161.

Sporn B. , 2001. Building Adaptive Universities: Emerging Organisational Forms Based on Experiences of European and US Universities. Tertiary Education and Management 7(2), 121-134.

Stephan P.E. and Levin S.G. , 2001. Career stage, benchmarking and collective research. International Journal of Technology Management 22(7), 676-687.

Thursby J. and Thursby M. , 2002. Who is selling the Ivory Tower? Sources of growth in university licensing. Management Science 48(1), 90-104.

Todorovic Z.W., McNaughton R.B.,Guild P. , 2005. Making university depart ments more entrepreneurial: the perspective from within. International Journal of Entrepreneurship and Innovation 6(2), 122. 
Todorovic Z.W., McNaughton R.B.,Guild P. , 2011. ENTRE-U: An entrepreneurial orientation scale for universities. Technovation 31(2-3), 128-137.

Tuunainen J. , 2005. Hybrid practices? Contributions to the debate on the mutation of science and university. Higher Education 50(2), 275-298.

Van Doorn, S., Jansen, J. J., Van den Bosch, F. A., Volberda, H. W., 2013. Entrepreneurial orientation and firm performance: Drawing attention to the senior team. Journal of Product Innovation Management 30(5), 821-836.

Van Looy B. , 2009. The Role of Entrepreneurial Universities within Innovation Systems. An Overview and Assessment. Review of Business and Economics 54(1), 62-81.

Van Looy B., Ranga M., Callaert J., Debackere K.,Zimmermann E. , 2004. Combining entrepreneurial and scientific performance in academia: towards a compounded and reciprocal Matthew-effect? Research Policy 33(3), 425-441.

Van Looy B., Landoni P., Callaert J., van Pottelsberghe B., Sapsalis E.,Debackere K. , 2011. Entrepreneurial effectiveness of European universities: An empirical assessment of antecedents and trade-offs. Research Policy 40(4), 553-564.

Yusof M. and Jain K., 2010. Categories of university-level entrepreneurship: a literature survey. International Entrepreneurship and Management Journal 6(1), 81-96.

Williams, E.E., 1983. Entrepreneurship, innovation and economic growth. Technovation 2(1), 3-15.

Wissema, J.G., 2009. Towards the third generation university: Managing the university in transition. Edward Elgar Publishing, Cheltenham, UK.

Wright M., Clarysse B., Lockett A. and Knockaert, M. 2008. Mid-range universities' linkages with industry: knowledge types and the role of intermediaries, Research Policy, 37 (8), pp. 1205-1223 


\section{Appendix: attitudinal variables for measuring entrepreneurial orientation (ENTRE-U)}

We must remark that this ENTRE-U scale was developed by Todorovic et al. (2005, 2011). The codes are own draft, according to the information in tables 2 and 3.

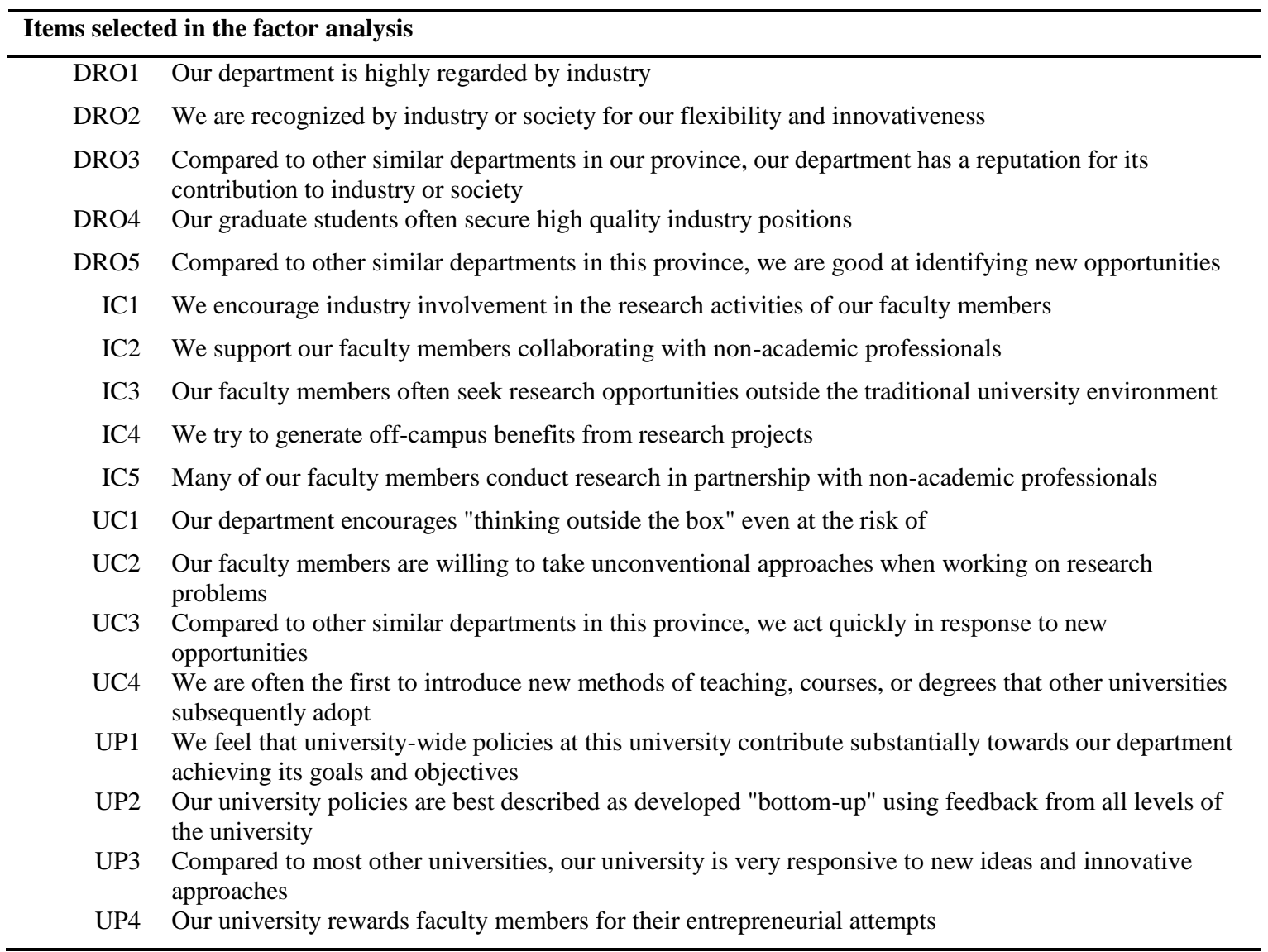




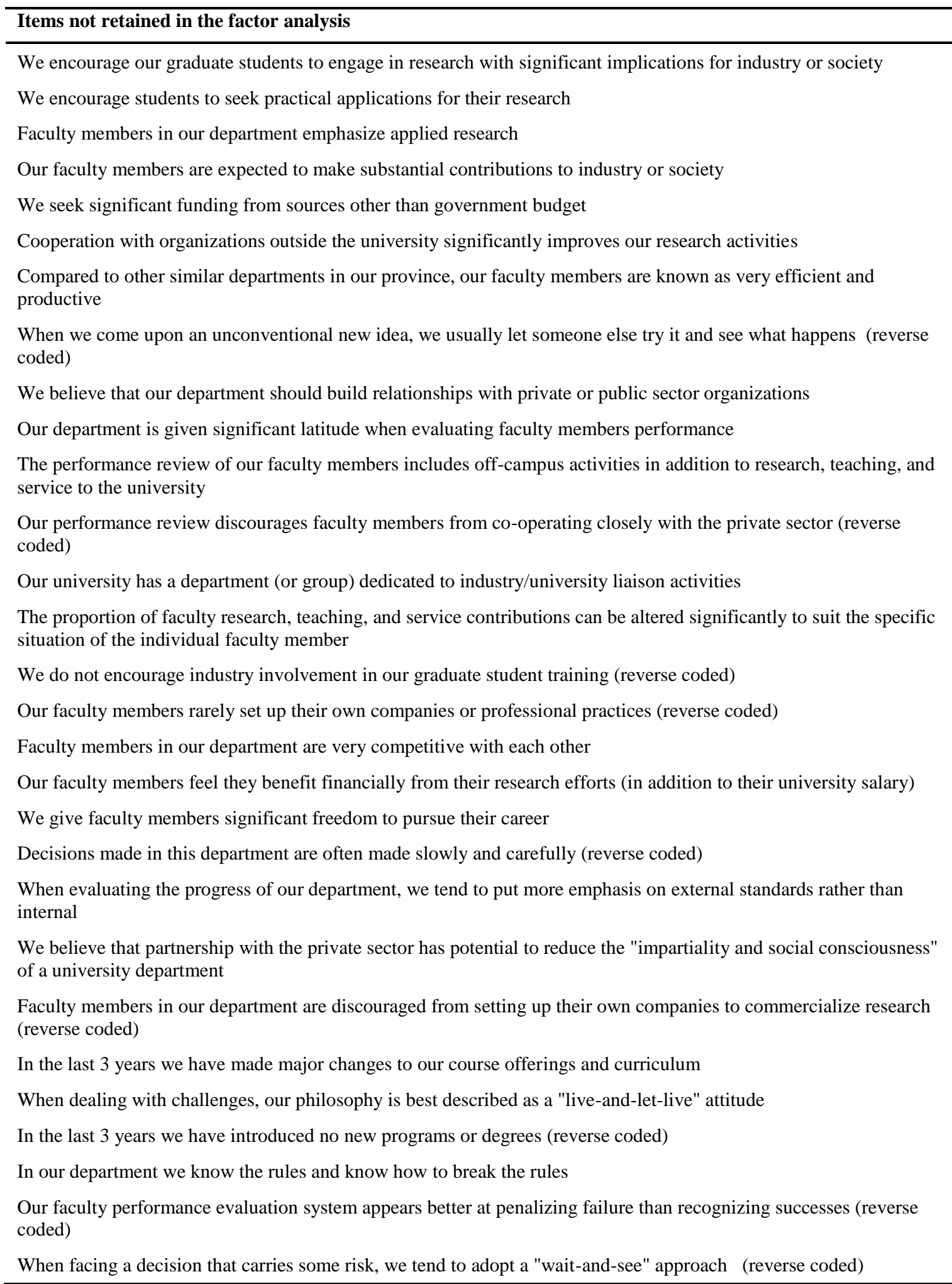

